\title{
Recent Developments In Blockchain
}

\author{
Angkita Bardhan \\ angkitabardhan14@gmail.com \\ Department of Mathematics, \\ University Institute of Sciences, \\ Chandigarh University, Gharuan, \\ Mohali, Punjab-140413, India
}

\begin{abstract}
The purpose of this paper is to provide an overview in the recent developments of Blockchain in various fields. In this paper, the storage structure of Blockchain is considered and how it differs from a database is discussed. Decentralization, transparency, Blockchain security, the relation of Bitcoin and Banks with Blockchain are all to consider. Uses of Blockchain, the advantages and disadvantages of Blockchain etc. discussed further. While the developments are reaching its peak each day, it is an important point which gives us the prediction that the Blockchain is going to give a future of higher achievements.
\end{abstract}

Keywords: Blockchain, Decentralization, Bitcoin, Banks, etc.

\section{Introduction}

A blockchain is a continuously increasing list of documents, known as blocks, that are connected together via encryption/cryptography. Blockchains are designed to be immutable and resistant to data modification. Communities, the decentralized Web, token economies, and worldwide peerto-peer data transfers, etc. are all made real by blockchain.

Although blockchain appears to be difficult, as it definitely can be one, but its underlying premise is actually extremely simple. A database, or blockchain, is a type of digital log. To recognize blockchain, it is necessary to first recognize what a database is. [2]

A database is a collection of data that is kept on a computer system in an electronic style. In databases, information, or data, is usually organized in table format to make searching and filtering for specific information simpler. What is the difference between a spreadsheet and a database when it comes in storing information?

Spreadsheets are meant to store and retrieve modest quantities of data for a single individual or a small group of people. A database, on the other hand, is designed to hold far greater volumes of data that can be accessed, filtered, and changed by any number of users at the same time. [7]

Large databases do this by storing information on servers comprised of sophisticated computers. In order to have the computing power and storage capacity required for many people to access the database at the same time, these servers can occasionally be created utilizing hundreds or thousands of computers. While a spreadsheet or database may be accessed by anyone, it is frequently owned by a company and maintained by a designated individual who has total control over how it functions and the data it contains. 
So, what makes a blockchain different from a database?

\section{Storage Structure}

The structure of data in a blockchain differs significantly from that of a traditional database. A blockchain is a digital ledger that gathers data in groupings called blocks, each of which contains a collection of data. When a block is filled, it is chained onto the previous full block, building a data chain known as the "blockchain." All new information that follows that newly added block is collected into a newly created block that will be added to the chain once it is filled.

A database organizes data into tables, but a blockchain organizes data into linked pieces (blocks). As a result, all blockchains are databases, but not every database is a blockchain. When implemented in a decentralized manner, this technology automatically creates an irreversible data timeline. When a block is filled, it becomes a constant part of the timeline. When a new block is added to the chain, it is allotted a precise timestamp. [2]

\section{Decentralization \& Distributed Ledger Technology (DLT)}

Decentralization is important to build a safe, non-discriminatory system. Blockchain uses a peerto-peer network and consensus algorithms to confirm transactions and record data, rather than depending on a central authority to do so. Architectural, political, and logical decentralization should be the goal of a unauthorized public network.

The term "decentralization" refers to the movement away from a centralized authority and toward multiple parties. The decentralized and distributed network of Blockchain solves the problem of double-spending without the need for a central counterparty. To create a safe, nondiscriminatory network, blockchain decentralization is necessary. To some extent, architectural, political, and logical decentralization is required. Scalability and efficiency are impacted by decentralization. [10]

It's helpful to think about blockchain in terms of how it's been implemented by Bitcoin to have a better grasp of it. Bitcoin, like a database, relies on a network of computers to keep its blockchain. This blockchain is just a sort of database that holds on to every Bitcoin transaction ever made for Bitcoin. In the case of Bitcoin, far from other databases, these computers are not all at the same location, and each computer or set of computers is run by a single person or group of people.

Consider a firm that has a server with 10,000 machines and a database that contains all of its customers' account information. This firm owns a facility that houses all of these machines and has complete control over all of the information they hold. Similarly, Bitcoin is made up of sets of computers, but each one or group of computers that carries the blockchain is positioned in a different part of the world and is run by a variety of people. The network of Bitcoin is made up of nodes, which are individual computers that make up the network. 
The blockchain of Bitcoin is used in a decentralized manner in the above concept. Private, centralized blockchains, on the other hand, exist in which all of the machines that make up the network are owned and managed by a single organization. [9]

Each node in a blockchain contains a complete record of all the data recorded on the blockchain from its beginning. The full history of all Bitcoin transactions is the data for Bitcoin. If a node's data has a mistake, it can fix itself by referencing the thousands of other nodes. This ensures that no one node in the network may change data. As a result, the transaction history in each block that makes up Bitcoin's blockchain is irreversible.

If one user vandalizes with the transaction record of Bitcoin, all other nodes will cross-reference each other, making it easy to find the node with the imprecise data. This approach aids in the creation of a precise and visible timeline. A blockchain can store a range of information, such as legal contracts, state identifications, or a company's product inventory. For Bitcoin, this information is a record of transactions, but a blockchain can also store legal contracts, state identifications, or a company's product inventory. [11]

A majority of the decentralized network's processing power would have to agree on the modifications in order to modify how that system functions or the information stored inside it. This guarantees that any changes do take place are in the majority's best interests.

\section{Transparency}

Because of the decentralized structure of Bitcoin's blockchain, all transactions may be transparently inspected by utilizing a personal node or blockchain explorers, which let anybody to witness transactions as they happen in real time. Each node maintains its own copy of the chain, which is updated when new blocks are verified and added. This means that you could follow Bitcoin throughout the world if you wanted to.

Exchanges, for example, have previously been hacked, resulting in the loss of every Bitcoin stored on the exchange. While the hacker may remain anonymous, the Bitcoins they stole may be tracked. It would be discovered if the Bitcoins stolen in some of these breaches were transferred or spent. [1]

\section{Blockchain Security}

Security and trust concerns are addressed in a number of ways with blockchain technology. To begin with, new blocks are always organized in a linear and chronological order. In other words, they are always appended to the "terminus" of blockchain. When you look at the Bitcoin blockchain, you'll see that each block has a "height," which is a location on the chain. The block's height had already reached 656,197 blocks as of November 2020.

It is extremely impossible to go back and change the contents of a block once it has been appended to the end of the blockchain unless the majority agrees. That's because each block includes its own hash, as well as the preceding block's hash and the time stamp indicated before. 
A math function converts digital data into a string of numbers and letters, which is then used to generate hash codes. The hash code changes if that information is altered in any manner.

Here's why that matters in terms of security. Let's assume a hacker wants to change the blockchain in order to steal Bitcoin from the rest of the world. If they alter their single copy, it would no longer match the copy of everyone else. When everyone else compares their copies, they'll see that this one stands out, and the hacker's version of the chain will be discarded as fraudulent. [9]

To succeed with such a compromise, the hacker would have to possess and change $51 \%$ of the blockchain copies at the same time, ensuring that their new copy becomes the majority copy and therefore the agreed-upon chain. An assault like this would cost a lot of money and resources since they'd have to rewrite all of the blocks because the timestamps and hash codes would be different today.

The expense of accomplishing such a feat would very certainly be impossible, given the scale of Bitcoin's network and its rapid growth. This would be not only prohibitively expensive, but also futile. Such a move would not go unnoticed by network participants, who would detect the blockchain being drastically altered. Members of the network would then split off to a new chain that was unaffected.

This would lead the value of the targeted version of Bitcoin to drop, rendering the assault useless because the bad actor would be in control of a worthless asset. If an unacceptable actor attacked Bitcoin's fresh fork, the same thing would happen. It's designed this way so that participating in the network is considerably more financially rewarding than attacking it. [10]

\section{Blockchain vs. Bitcoin}

The objective of blockchain is to enable the recording and distribution of digital data without the ability to modify it. Stuart Haber and W. Scott Stornetta, two researchers, originally proposed blockchain technology in 1991, with the goal of creating a system that could not be manipulated with when it came to document timestamps. However, blockchain did not have its first realworld use until over two decades later, with the introduction of Bitcoin in January 2009.

A blockchain is the base of the Bitcoin protocol. Bitcoin's pseudonymous developer, Satoshi Nakamoto, described the digital currency as "a new electronic cash system that's entirely peer-topeer, with no trusted third party" in a research paper introducing it.

The important thing to remember is that Bitcoin only utilizes blockchain to create a transparent ledger of payments; however, blockchain may theoretically be used to immutably record any amount of data items. As previously said, this may take the shape of transactions, election votes, goods inventories, state identifications, house deeds, and much more.

There are already a slew of blockchain-based initiatives attempting to use the technology for purposes other than transaction recording. The use of blockchain in voting during democratic 
elections is an excellent example. The immutability of blockchain makes fraudulent voting much more difficult.

A voting system, for example, might be set up such that each citizen of a nation receives a separate coin or token. Each candidate would then be assigned a unique wallet address, and voters would transfer their tokens or crypto to the address of the candidate they desire to support. Because blockchain is transparent and traceable, it eliminates the need for human vote counting and the possibility of bad actors to interfere with physical votes. [3]

\section{Blockchain vs. Banks}

Decentralized Blockchains and Banks are radically different. Let's compare the banking system to Bitcoin's implementation of blockchain to understand how it varies from blockchain. [6]

\begin{tabular}{|c|c|c|}
\hline Feature & Banks & Bitcoin \\
\hline Simplicity of Transfers & $\begin{array}{l}\text { The minimal prerequisites for } \\
\text { digital transfers are } \\
\text { government-issued identity, a } \\
\text { bank account, and a mobile } \\
\text { phone. }\end{array}$ & $\begin{array}{l}\text { The bare minimum is an } \\
\text { internet connection and a } \\
\text { mobile phone. }\end{array}$ \\
\hline Know Your Customer Rules & $\begin{array}{l}\text { "Know Your Customer" } \\
\text { (KYC) processes are required } \\
\text { for bank accounts and other } \\
\text { financial products. This } \\
\text { implies that banks are } \\
\text { obligated by law to keep track } \\
\text { of a customer's identification } \\
\text { before creating an account. }\end{array}$ & $\begin{array}{l}\text { Without identity, anyone or } \\
\text { anything may join the network } \\
\text { of Bitcoin. In principle, even } \\
\text { an artificial intelligence- } \\
\text { enabled entity might take part. }\end{array}$ \\
\hline Privacy & $\begin{array}{l}\text { The client's bank account } \\
\text { information is saved on the } \\
\text { bank's private servers. The } \\
\text { privacy of a bank account is } \\
\text { just as safe as the bank's } \\
\text { servers and how effectively } \\
\text { the individual user encrypts } \\
\text { their personal information. If } \\
\text { the bank's systems are hacked, } \\
\text { the individual's account will } \\
\text { be hacked as well. }\end{array}$ & $\begin{array}{l}\text { Bitcoin users may keep their } \\
\text { transactions as secret as they } \\
\text { like. Although every Bitcoin } \\
\text { may be traced, it is hard to } \\
\text { determine who owns Bitcoin if } \\
\text { it was acquired anonymously. } \\
\text { When Bitcoin is acquired } \\
\text { through a KYC exchange, the } \\
\text { Bitcoin is linked to the } \\
\text { account holder of the KYC } \\
\text { exchange. }\end{array}$ \\
\hline Transaction Fees & $\begin{array}{l}\text { Card Payments: This charge } \\
\text { varies per card and is not paid } \\
\text { directly by the user. Stores pay } \\
\text { fees to payment processors, } \\
\text { which are typically levied per } \\
\text { transaction. This charge has } \\
\text { the potential to raise the cost }\end{array}$ & $\begin{array}{l}\text { Bitcoin transaction costs are } \\
\text { decided by both miners and } \\
\text { users. This charge can be } \\
\text { anything from } \$ 0 \text { to } \$ 50 \text {, but } \\
\text { consumers have the option of } \\
\text { deciding how much they are } \\
\text { prepared to spend. This }\end{array}$ \\
\hline
\end{tabular}




\begin{tabular}{|c|c|c|}
\hline & $\begin{array}{l}\text { of products and services. } \\
\text { Checks: Depending on your } \\
\text { bank, checks might cost } \\
\text { anywhere from } \$ 1 \text { to } \$ 30 \text {. } \\
\text { Automated Clearing House } \\
\text { (ACH): When transferring to } \\
\text { external accounts, ACH } \\
\text { transactions might cost up to } \\
\$ 3 \text {. } \\
\text { Wire: Outgoing domestic wire } \\
\text { transfers may be as expensive } \\
\text { as } \$ 25 \text {. International wire } \\
\text { transfers can be as expensive } \\
\text { as } \$ 45 \text {. }\end{array}$ & $\begin{array}{l}\text { provides an open market } \\
\text { where if a user's charge is set } \\
\text { too low, the transaction may } \\
\text { not be completed. }\end{array}$ \\
\hline Transaction Speed & $\begin{array}{l}\text { Payments via credit card take } \\
24-48 \text { hours to process. } \\
\text { Checks take } 24-72 \text { hours to } \\
\text { clear, whereas ACH takes } 24- \\
48 \text { hours. } \\
\text { Unless it's an overseas order, } \\
\text { outgoing domestic wire } \\
\text { transfers is done within } 24 \\
\text { hours. On weekends and } \\
\text { holidays, bank transfers are } \\
\text { usually not completed. }\end{array}$ & $\begin{array}{l}\begin{array}{l}\text { Depending on } \\
\text { congestion, } \\
\text { transactions might } \\
\text { anywhere from } \\
\text { over an hour. }\end{array} \\
\begin{array}{l}\text { Bitcoin } \\
\text { ovinutes to }\end{array} \\
\end{array}$ \\
\hline Account Seizures & $\begin{array}{l}\text { Governments can easily trace } \\
\text { people's bank accounts and } \\
\text { confiscate the assets contained } \\
\text { inside them thanks to KYC } \\
\text { rules. }\end{array}$ & $\begin{array}{l}\text { Governments would have a } \\
\text { difficult time tracking down } \\
\text { and seizing Bitcoin if it is used } \\
\text { anonymously. }\end{array}$ \\
\hline Open Hours & $\begin{array}{l}\text { On weekdays, traditional } \\
\text { brick-and-mortar banks are } \\
\text { open from 9:00 a.m. to 5:00 } \\
\text { p.m. Some banks are open on } \\
\text { weekends, but only for a short } \\
\text { amount of time. No Banks are } \\
\text { open on Banking holidays. }\end{array}$ & $\begin{array}{l}\text { There are no defined hours; it } \\
\text { is open } 24 \text { hours a day, } 365 \\
\text { days a year. }\end{array}$ \\
\hline Approved Transactions & $\begin{array}{l}\text { For a number of reasons, } \\
\text { banks have the right to refuse } \\
\text { transactions. Banks also have } \\
\text { the right to put account freezes }\end{array}$ & $\begin{array}{l}\text { The Bitcoin network itself has } \\
\text { no influence on how Bitcoin is } \\
\text { utilized in any way. Users can } \\
\text { use Bitcoin as they choose, but }\end{array}$ \\
\hline
\end{tabular}




\begin{tabular}{|c|c|c|}
\hline & $\begin{array}{l}\text { in place. Purchases made in } \\
\text { odd areas or for unusual } \\
\text { products may be rejected by } \\
\text { your bank. }\end{array}$ & $\begin{array}{l}\text { they must follow the rules of } \\
\text { their nation or area. }\end{array}$ \\
\hline Security & $\begin{array}{l}\text { A bank account's information } \\
\text { is only as safe as the bank's } \\
\text { server that stores client } \\
\text { account information, assuming } \\
\text { the customer uses strong } \\
\text { internet security precautions } \\
\text { such utilizing secure } \\
\text { passwords and two-factor } \\
\text { authentication. }\end{array}$ & $\begin{array}{l}\text { The Bitcoin network becomes } \\
\text { more secure as it expands in } \\
\text { size. A Bitcoin owner's level } \\
\text { of security with their own } \\
\text { Bitcoin is totally up to them. } \\
\text { As a result, it is advised that } \\
\text { greater amounts of Bitcoin, or } \\
\text { any quantity meant to be } \\
\text { retained for a lengthy period } \\
\text { of time, be stored in cold } \\
\text { storage. }\end{array}$ \\
\hline
\end{tabular}

\section{Applications of Blockchain}

Blocks on Bitcoin's blockchain, as we now know, hold data about monetary transactions. However, it turns out that blockchain may also be used to store data about other sorts of transactions.

Walmart, Pfizer, AIG (American International Group, Inc.) Siemens, Unilever, and a lot of other firms have already used blockchain technology. IBM (International Business Machines), for example, has developed its Food Trust blockchain to track the path that food goods follow to reach their destinations. [6]

What is the need of doing this? Countless outbreaks of E. coli, salmonella, and listeria, as well as hazardous chemicals unintentionally introduced to meals, have occurred in the food sector. It used to take weeks to figure out what was causing these outbreaks or what was causing people to become sick from what they were consuming.

Brands can track a food product's journey from its origin through each stop it takes, and eventually to its delivery, using blockchain. If a meal is determined to be tainted, it may be tracked back to its source via each stop. Not only that, but these firms can now see everything else they have come into touch with, perhaps saving lives by allowing the problem to be identified far sooner. This is one example of a blockchain in action, but there are many more ways to build a blockchain.

\subsection{Banking and Finance}

Banking is one of the industries that stands to gain the most from incorporating blockchain into its operations. Financial institutions are only open five days a week during regular business 
hours. For example, if you try to deposit a check at 6 p.m. on Friday, you'll most likely have to wait until Monday morning to see the funds in your account. Even if you make your deposit during business hours, due to the large volume of transactions that banks must settle, it may take one to three days for the transaction to be verified. On the contrary, Blockchain never sleeps.

Consumers may see their transactions executed in as little as 5 minutes by integrating blockchain into banks, the time it takes to add a block to the blockchain, regardless of any amount of time in a day. Banks may now trade funds across organizations more swiftly and safely with the help of blockchain. The settlement and clearing procedure in the stock trading industry, for example, can take up to three days (or more if dealing abroad), which means that the money and shares are frozen during that time.

Because of the large quantities involved, even a few days in transit can result in substantial expenses and hazards for institutions. The potential savings, according to European bank Santander and its research partners, range from $\$ 15$ billion to $\$ 20$ billion each year. According to Capgemini, a French consulting firm, blockchain-based apps may save customers up to $\$ 16$ billion in banking and insurance expenses each year. [4]

\subsection{Currency}

For cryptocurrencies like Bitcoin, blockchain is the foundation. The Federal Reserve manages the value of the US currency. A user's data and cash are subject to the whims of their bank or government under this central authority arrangement. If a user's bank gets hacked, the client's personal data is exposed. The value of a client's money may be jeopardized if their bank goes bankrupt or if they live in a nation with an unstable government. In 2008, public money was used to bail out some of the banks that had run out of cash. These were the concerns that led to the creation and development of Bitcoin.

Bitcoin and other cryptocurrencies may operate without the need for a central authority because blockchain distributes its activities over a network of computers. This not only lowers the risk, but it also removes many of the transaction and processing expenses. It can also provide a more stable currency with more uses and a larger network of persons and organizations with whom to do business both domestically and globally for those in nations with unsteady currencies or financial infrastructures. [6]

For people who do not have state identification, using bitcoin wallets for savings accounts or as a means of payment is extremely important. Some nations may be in the midst of a civil war, or their governments may lack the necessary infrastructure to give identity. Citizens of such nations may be unable to open savings or brokerage accounts, leaving them with no means of safely storing wealth.

\subsection{Healthcare}

Health-care professionals may use blockchain to keep their patients' medical records in a safe manner. When a medical record is created and signed, it may be stored on the blockchain, giving patients confirmation and assurance that the record cannot be altered. These personal health 
records may be encrypted and kept on the blockchain using a private key, guaranteeing that only specific people have access to them. [5]

\subsection{Records of Property}

If you've ever visited your local Recorder's Office, you know how inefficient and timeconsuming the process of documenting property rights is. A physical deed is still required to be handed to a government employee at the local recording office, where it is manually recorded into the county's central database and public index. Property claims must be reconciled with the public index in the case of a property dispute.

This procedure is not only costly and time-consuming, but it is also prone to human mistake, with each inaccuracy reducing the efficiency of property ownership monitoring. Scanning papers and chasing down actual files in a local recording office might be obsolete thanks to blockchain. Property owners may trust that their deed is accurate and permanently documented if it is saved and validated on the blockchain.

It can be virtually hard to prove ownership of a property in war-torn nations or places with little to no government or financial infrastructure, and certainly no "Recorder's Office." Property ownership timeframes might be established in a transparent and unambiguous manner if a group of individuals living in such a region is able to use blockchain. [3]

\subsection{Smart Contracts}

A smart contract is a piece of computer code that can be built in the blockchain to help facilitate, verify, or negotiate a contract. Users agree to a set of criteria for smart contracts to work. The provisions of the agreement are automatically carried out whenever those requirements are satisfied.

Suppose a prospective renter wants to lease an apartment using a smart contract. When the renter pays the security deposit, the landlord agrees to provide the tenant the apartment's door code. Both the renter and the landlord would transmit their sections of the agreement to the smart contract, which would keep track of the door code and immediately alter it for the security deposit on the starting date of the lease. The security deposit is returned if the landlord is unsuccessful to provide the door code by the lease date. This would remove the expenses and processes involved with using a notary, third-party mediator, or attorneys.

\subsection{Supply Chains}

As in the IBM Food Trust example, suppliers can use blockchain to keep in records the origins of materials that they have purchased. This would allow companies to check the authenticity of their products, along with such common tags as "Organic," "Local," and "Fair Trade."

As recorded by Forbes, the food industry is rapidly adopting the use of blockchain to track the path and safety of food throughout the farm-to-user journey. [5] 


\subsection{Voting}

As previously said, blockchain may be utilized to advance in the development of a modern voting system. As illustrated in the November 2018 midterm elections in West Virginia, voting with the help of blockchain has the ability to eradicate election fraud and increase voter come to light. Using blockchain in this way would make vandalizing with votes almost difficult. The blockchain technology will also ensure electoral openness by reducing the number of people required to run an election and giving officials with near-instant results. There would be no need for re-counts, and there would be no serious peril that the election would be maligned by fraud.

\section{Advantages and Disadvantages of Blockchain}

Despite its intricacy, the potential of Blockchain as a decentralized record-keeping system is nearly without any limitation. Ranging from increased user privacy and security to reduced processing fees and fewer mistakes, Blockchain technology may have uses beyond those listed above. However, there are certain drawbacks too.

\subsection{Advantages}

- Increased accuracy by eliminating the need for human verification.

- Cost savings by terminating the need for third-party verification

- Decentralization makes it more difficult to tamper with data.

- Transactions are safe, secure, and quick.

- Technology that is transparent

- Provides people of nations with insecure or undeveloped governments with a banking option and a method to safeguard personal information.

\subsection{Disadvantages}

- Bitcoin mining has an outstanding technological cost

- Low transaction rate per second.

- Use in illegal acts in History.

- Modulation.

\section{Future for Blockchain}

Blockchain, which was first suggested as a research project in 1991, is now settling in its late twenties comfortably. Blockchain, like most millennials its age, has had a lot of press in the previous two decades, with companies all around the globe speculating on what the technology can do and where it will go in the future.

With numerous practical applications for the technology now being implemented and investigated, blockchain, at the age of twenty-seven, is finally establishing a name for itself, thanks in no little part to bitcoin and cryptocurrencies. Blockchain, a phrase on the lips of every 
investor in the country, promises to make corporate and government processes more precise, efficient, secure, and cost-effective by eliminating middlemen.

It's no longer a matter of "if" legacy firms will adopt blockchain—rather now it's question of "when." As we enter the third decade of blockchain, it's no longer a question of "if." [8]

\section{Conclusion}

In this paper, the concepts of Blockchain along with its development in various sectors, especially its relation with Bitcoin and Banks is discussed. In the late twenties, blockchain is a vitally important trending technology. Blockchain is being considered as being created day by day and achieving new heights of success in this huge technological environment. A vision of the future of Blockchain is presented in the paper. Blockchain technology provides a wide range of applications in a variety of sectors. The ability of blockchain as a decentralized record-keeping system is essentially infinite, notwithstanding its difficulties. Beyond the benefits listed above, blockchain technology can provide improved customer safety and protection, as well as cheaper transaction costs and fewer mistakes. The entire potential of Blockchain technology is yet to bring to light.

\section{Acknowledgement}

I would like to show my special thanks of gratitude to my Professor Dr. R. N. Prajapati as well as our Department of Mathematics, Chandigarh University who gave me the golden opportunity to do this paper, this also encouraged me in conducting extensive research and learning about a variety of new topics.

\section{References}

[1] Wei Cai, Zehua Wang, Jason B Ernst, Zhen Hong, Chen Feng, and Vic-tor CM Leung. Decentralized applications: The blockchain-empowered software system. IEEE Access, 6:53019-53033, 2018.

[2] Vikram Dhillon, David Metcalf, and Max Hooper. Recent develop- ments in blockchain. In Blockchain Enabled Applications, pages 151-181.Springer, 2017.

[3] Mark Fenwick and Erik PM Vermeulen. Technology and corporate governance: Blockchain, crypto, and artificial intelligence. Tex. J. Bus. L., 48:1, 2019.

[4] Oliver R Kabi and Virginia NL Franqueira. Blockchain-based distributed marketplace. In International Conference on Business Information Sys- tems, pages 197-210. Springer, 2018.

[5] Marc Pilkington. Blockchain technology: principles and applications. In Research handbook on digital transformations. Edward Elgar Publishing, 2016.

[6] Marten Risius and Kai Spohrer. A blockchain research framework. Busi-ness \& Information Systems Engineering, 59(6):385-409, 2017. 
[7] Johannes Sedlmeir, Hans Ulrich Buhl, Gilbert Fridgen, and Robert Keller. Recent developments in blockchain technology and their impact on energy consumption. arXiv preprint arXiv:2102.07886, 2021.

[8] Zibin Zheng, Shaoan Xie, Hong-Ning Dai, Xiangping Chen, and Huaimin Wang. Blockchain challenges and opportunities: A survey. International Journal of Web and Grid Services, 14(4):352-375, 2018.

[9] Atzori, M., 2015. Blockchain technology and decentralized governance: is the state still necessary?(2015). Retrieved September, 1, p.2017.

[10]Gencer, A.E., Basu, S., Eyal, I., Van Renesse, R. and Sirer, E.G., 2018, February. Decentralization in bitcoin and ethereum networks. In International Conference on Financial Cryptography and Data Security (pp. 439-457). Springer, Berlin, Heidelberg.

[11]Walch, A., 2019. Deconstructing'Decentralization': Exploring the Core Claim of Crypto Systems. Crypto Assets: Legal and Monetary Perspectives (OUP, Forthcoming). 